\title{
LANGKAH KECIL SEMA FAKULTAS EKONOMI UNTUK KEPEDULIAN BESAR DALAM MENGABDI KEPADA MASYARAKAT
}

\author{
Bambang Susanto ${ }^{1}$, R. Aryanti Ratnawati ${ }^{2}$, Tasya Nurahliana ${ }^{3}$, M. Hafiz Akmal Nugraha ${ }^{4}$, \\ Tri Nuryanti ${ }^{5}$, Sindi Yasinta ${ }^{6}$, Pitri Novianti ${ }^{7}$, Nurhidayati Putri ${ }^{8}$, Pusvita Ira ${ }^{9}$, Yuni \\ Indriani $^{10}$, Fajar ${ }^{11}$, Nursahidah ${ }^{12}$, Terezinha Pereira Barreto ${ }^{13}$, Fauzi Ramadhan $S^{14}$, Windi \\ Lestari $^{15}$, Dyah Saputri ${ }^{16}$, Aghnia Rusyda ${ }^{17}$, Siti Meli ${ }^{18}$, Dhera Aditia ${ }^{19}$, Ira Setiawati ${ }^{20}$, Delvi \\ Yulianda $^{21}$, Hasna Nur Azizah ${ }^{22}$, Resyifa Dirdantini ${ }^{23}$, Nenny Hendajany ${ }^{24}$ \\ 1,2,3,4,5,6,7,8,9,10,11,12,13,14,15,16,17,18,19,20,21,22,24 Fakultas Ekonomi, Universitas Sangga Buana \\ ${ }^{1}$ korespondensi : bambang.susanto@usbypkp.ac.id
}

\begin{abstract}
ABSTRAK
Senat Mahasiswa (SEMA) merupakan suatu lembaga organisasi yang berperan melaksanakan kegiatan kemahasiswaan di lingkungan Fakultas. SEMA Fakultas Ekonomi memiliki beberapa program kerja, yang pada dasarnya mengutamakan kebermanfaatan, baik bagi internal maupun eksternal, salah satunya adalah program Pengabdian Kepada Masyarakat (PKM). Program PKM dilakukan di Desa Mangunjaya, Kabupaten Bandung selama 4 hari dengan metode pembelajaran konsep masyarakat tradisional. Dengan adanya kegiatan PKM ini, diharapkan dapat semakin menumbuhkan jiwa dan nilai sosial, serta penguatan karakter para anggota SEMA. Selain itu, langkah kecil yang dilakukan oleh SEMA Fakultas Ekonomi ini semoga bisa memberikan manfaat yang besar bagi warga desa.
\end{abstract}

Kata Kunci: Pengabdian kepada Masyarakat, Kepedulian, Desa

\begin{abstract}
The Student Senate (SEMA) is an organization that plays a role in carrying out student activities within the Faculty. SEMA Faculty of Economics has several work programs, which basically prioritize benefits, both internal and external, one of which is the Community Service Program (PKM). The PKM program was conducted in Mangunjaya Village, Bandung Regency for 4 days using the traditional community concept learning method. PKM activity is expected to further grow the spirit and social values, as well as strengthening the character of the members of SEMA. In addition, the small steps taken by SEMA of the Faculty of Economics hopefully can provide great benefits for villagers.
\end{abstract}

Keywords: Community Service, Concern, Village

\section{PENDAHULUAN}

Senat Mahasiswa (SEMA) merupakan suatu beberapa program kerja, yang pada dasarnya lembaga organisasi yang berperan melaksanakan kegiatan kemahasiswaan di lingkungan Fakultas. Di Universitas Sangga Buana, SENAT Fakultas Ekonomi, menaungi beberapa jurusan, yaitu S1 Manajemen, S1 Akuntasi, D3 Akuntansi dan D3 Keuangan dan Perbankan. SEMA Fakultas Ekonomi memiliki mengutamakan kebermanfaatan, baik bagi internal maupun eksternal.

Salah satu program kerja yang dimiliki adalah Pengabdian kepada Masyarakat (PKM). Menurut UU No. 12 tahun 2012, Pengabdian kepada Masyarakat adalah kegiatan sivitas 
akademika yang memanfaatkan Ilmu Pengetahuan dan Teknologi untuk memajukan kesejahteraan masyarakat dan mencerdaskan kehidupan bangsa [1] . Program kerja PKM ini diharapkan dapat dijadikan suatu sarana pengamalan jiwa dan nilai sosial, seperti: kesederhanaan, kejujuran dan kebersamaan.

Zaman sekarang adalah zaman asosiasi antara Timur dan Barat, yakni zaman adanya hubungan dan percampuran kultur Timur dan kultur Barat [2]. Dikarenakan hal tersebut, beberapa karakter dan kebudayaan bangsa Indonesia saat ini sudah mulai hilang, terutama di kalangan anak muda, yang merupakan generasi penerus bangsa. Dalam PKM ini ditanamkan kembali budaya gotong-royong dan demokrasi, serta sikap ramah, religious, dan toleransi.

\section{METODE}

Program kerja PKM ini dilakukan dengan metode pembelajaran konsep masyarakat tradisional, sehingga masyarakat yg menjadi sasaran adalah masyarakat desa. Kegiatan PKM dilakukan di Desa Mangunjaya, Kecamatan Arjasari, Kabupaten Bandung.

Pengabdian Pada Masyarakat merupakan sebuah kegiatan pembelajaran untuk mengenal sebuah lingkungan penduduk desa. Oleh karena itu, pada kegiatan PKM ini, semua anggota SEMA mengikuti seluruh kegiatan rutin penduduk desa, baik dirumah maupun saat bekerja diluar.

\section{HASIL DAN PEMBAHASAN}

PKM dilakukan selama 4 hari, mulai dari tanggal 7 sampai dengan 10 Maret 2019. Sasaran kegiatan mencakup seluruh lapisan masyarakat, mulai dari anak-anak, remaja, hingga masyarakat umum lainnya. Beberapa kegiatan yang dilakukan diantaranya adalah pelaksanaan Seminar Motivasi Kuliah dan Seminar Kepemimpinan. Sasaran dari kegiatan ini adalah remaja Desa Mangunjaya, baik yang masih duduk di bangku SMA/sederajat ataupun yang sudah lulus sekolah.

Kedua seminar ini dirasa sangat perlu diberikan, mengingat pentingnya manfaat dari kedua materi seminar tersebut. Motivasi berfungsi sebagai pendorong kemampuan, usaha, keinginan, dan mengarahkan perilaku/tindakan seseorang [3]. Dengan adanya Seminar Motivasi Kuliah yang diberikan oleh anggota SEMA, diharapkan para remaja Desa Mangunjaya menjadi terdorong untuk menempuh pendidikan sampai ke jenjang yang tertinggi.

Sementara kepemimpinan adalah suatu karakter dan/atau kemampuan untuk mempengaruhi orang lain atau kelompok agar bertindak seperti yang diharapkan sehingga dapat mencapai tujuan secara efektif dan efisien [4]. Kepemimpinan ini sangat penting bagi para remaja Desa Mangunjaya, karena tentunya pada masa yang akan datang, mereka akan menggantikan para pemimpin yang sedang menjabat pada masa sekarang. Terlepas dari itu, bagi para remaja laki-laki, mereka pun 
kelak akan menjadi pemimpin di keluarganya masing-masing. Oleh karena itu, melalui Seminar Kepemimpinan ini, dijelaskan apa saja karakter-karakter yang harus dimiliki oleh seorang pemimpin dan bagaimana cara memimpin suatu organisasi dengan baik.

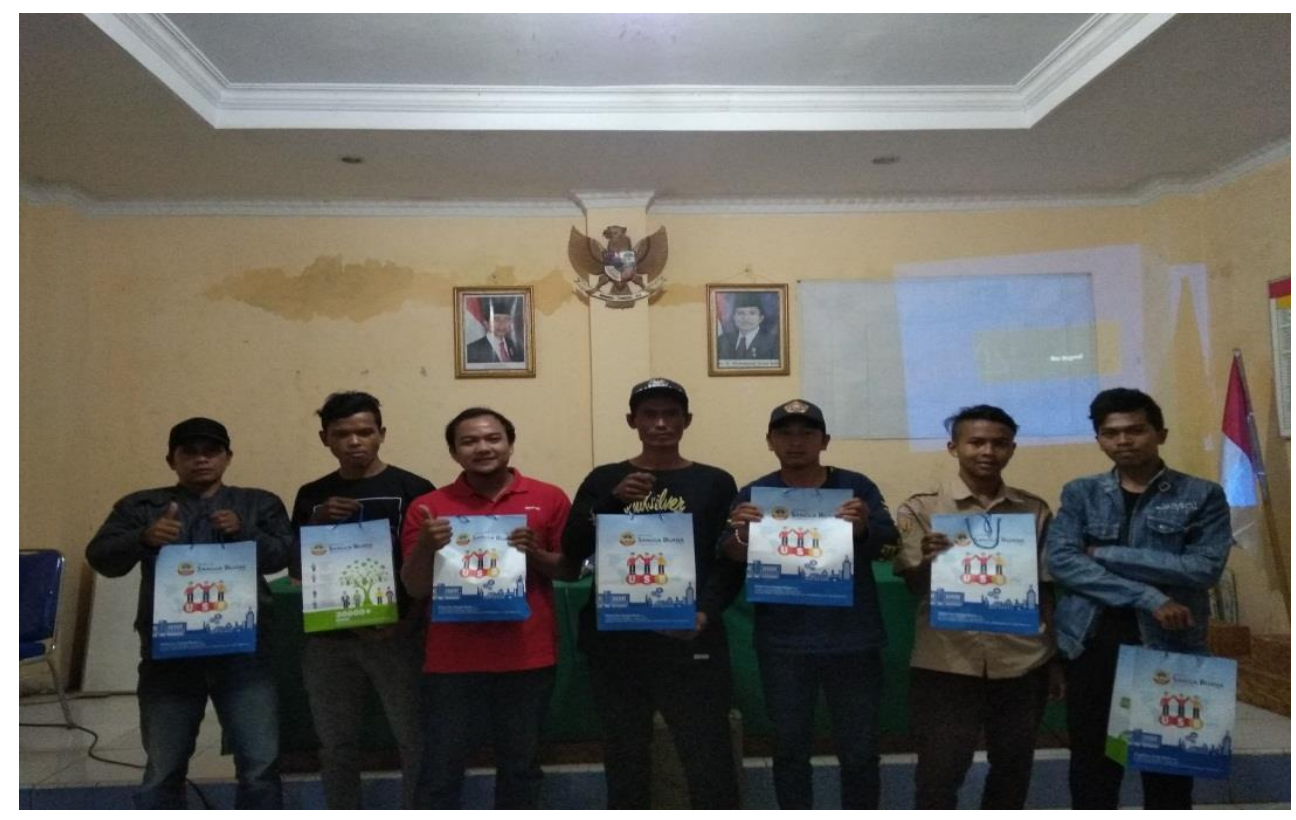

Gambar 1 : Pemuda Desa Mangunjaya Menerima Materi Seminar Kepemimpinan

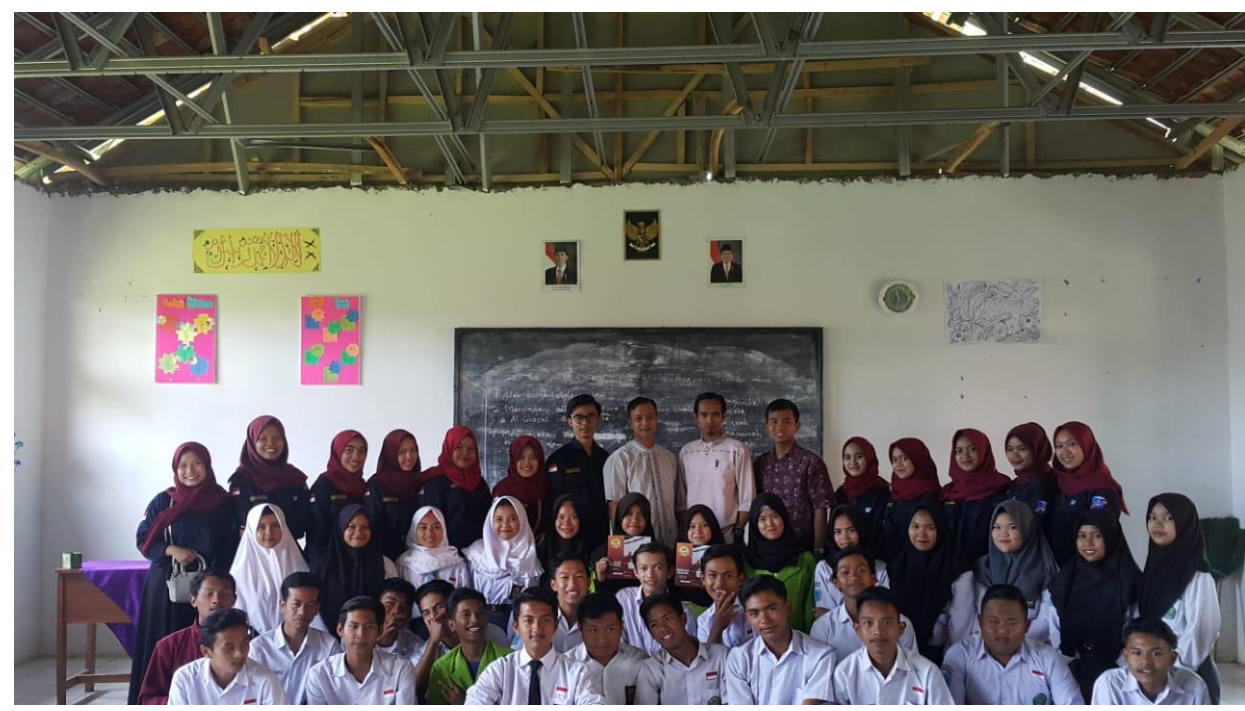

Gambar 2 : Pemberian Seminar Motivasi Kuliah untuk Siswa SMA

Sementara untuk para siswa TK, diadakan kegiatan melukis celengan. Hal ini bermanfaat untuk melatih kreatifitas anak- anak Desa Mangunjaya. Selain itu, kegiatan ini juga berguna untuk menumbuhkan rasa kasih sayang dan melatih kesabaran para 
anggota SEMA. Celengan yang telah para siswa untuk mulai belajar menabung dilukis tersebut juga bisa digunakan oleh sedari dini.

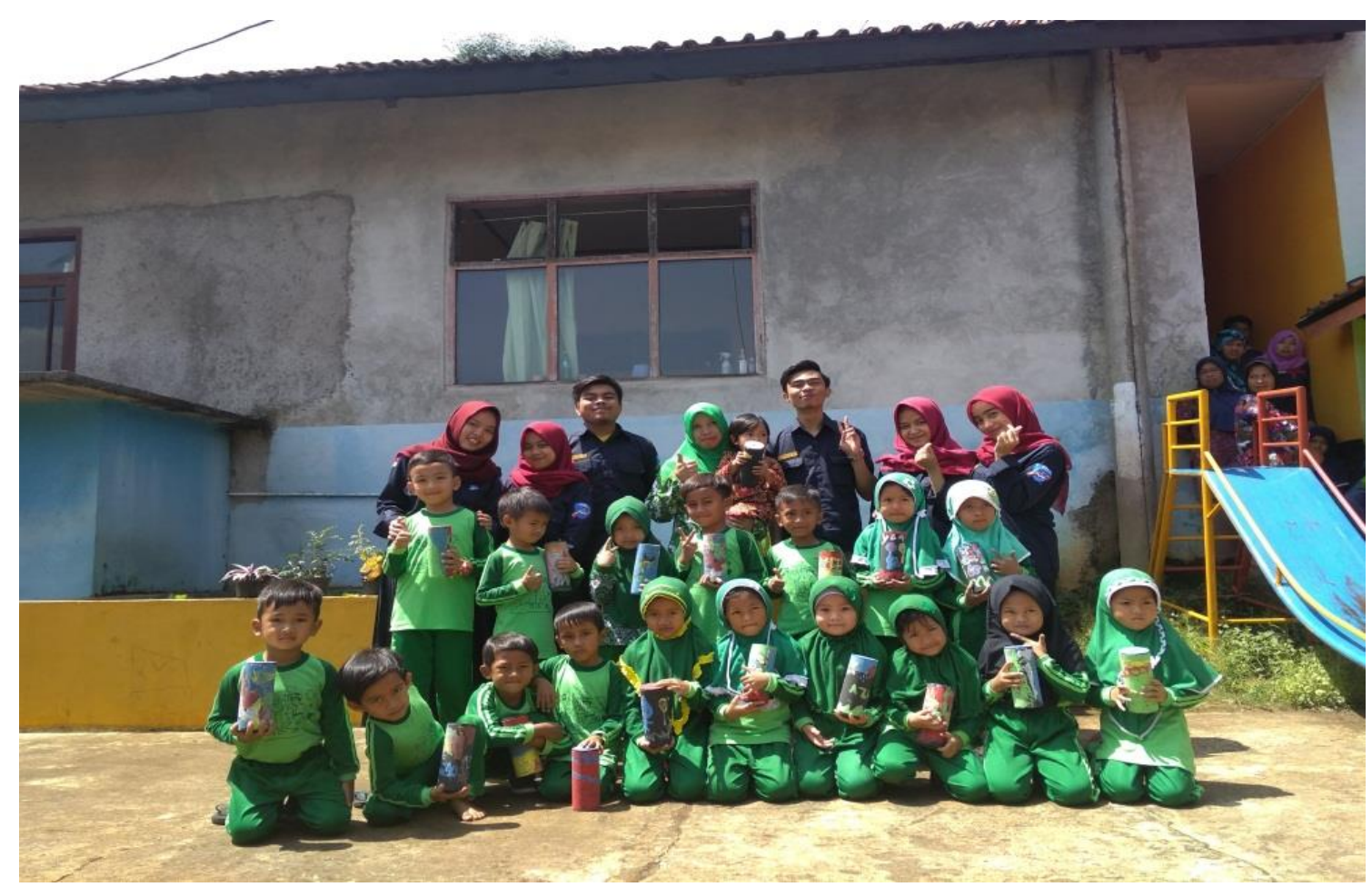

Gambar 3 : Siswa TK Desa Mangunjaya Menunjukkan Hasil Karya Celengan yang Telah Dilukis

Untuk para siswa SD, diadakan kegiatan Lomba Cerdas Cermat. Kegiatan ini berguna untuk menguji dan meningkatkan wawasan para siswa. Selain itu, dengan dilaksanakannya Lomba Cerdas Cermat ini bisa melatih jiwa kompetitif para siswa, karena dari pihak SEMA disediakan hadiah untuk pemenang lomba tersebut. Kompetitif adalah dorongan untuk meningkatkan kualitas diri agar menjadi lebih baik lagi atau memenuhi standar keberhasilan [5]. Jiwa kompetitif ini juga sangat penting bagi para siswa tersebut, terutama dalam menghadapi persaingan global yang semakin ketat. Dengan memiliki jiwa kompetitif, para generasi penerus bangsa ini akan senantiasa memperbaiki kualitas diri dan selalu mencoba melakukan yang terbaik dalam segala hal. 


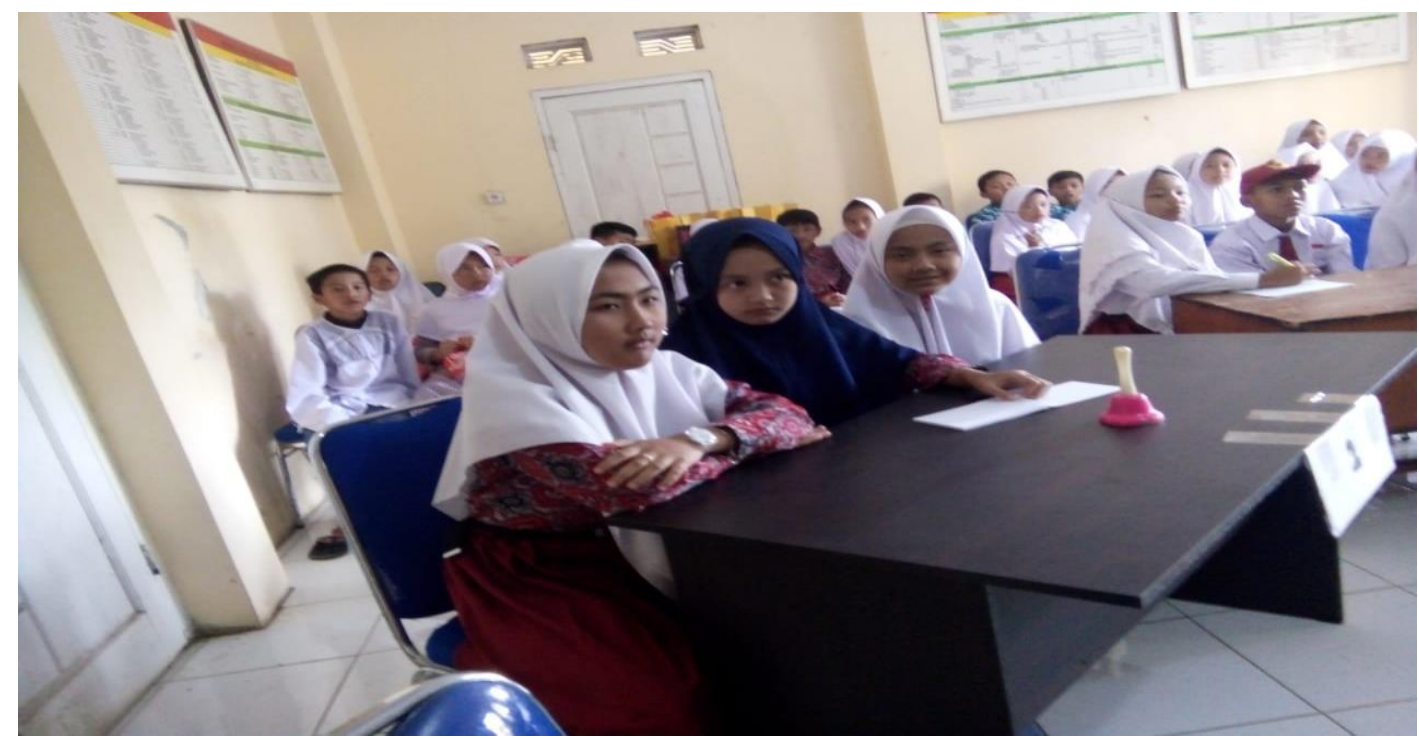

Gambar 4 : Lomba Cerdas Cermat untuk Siswa SD

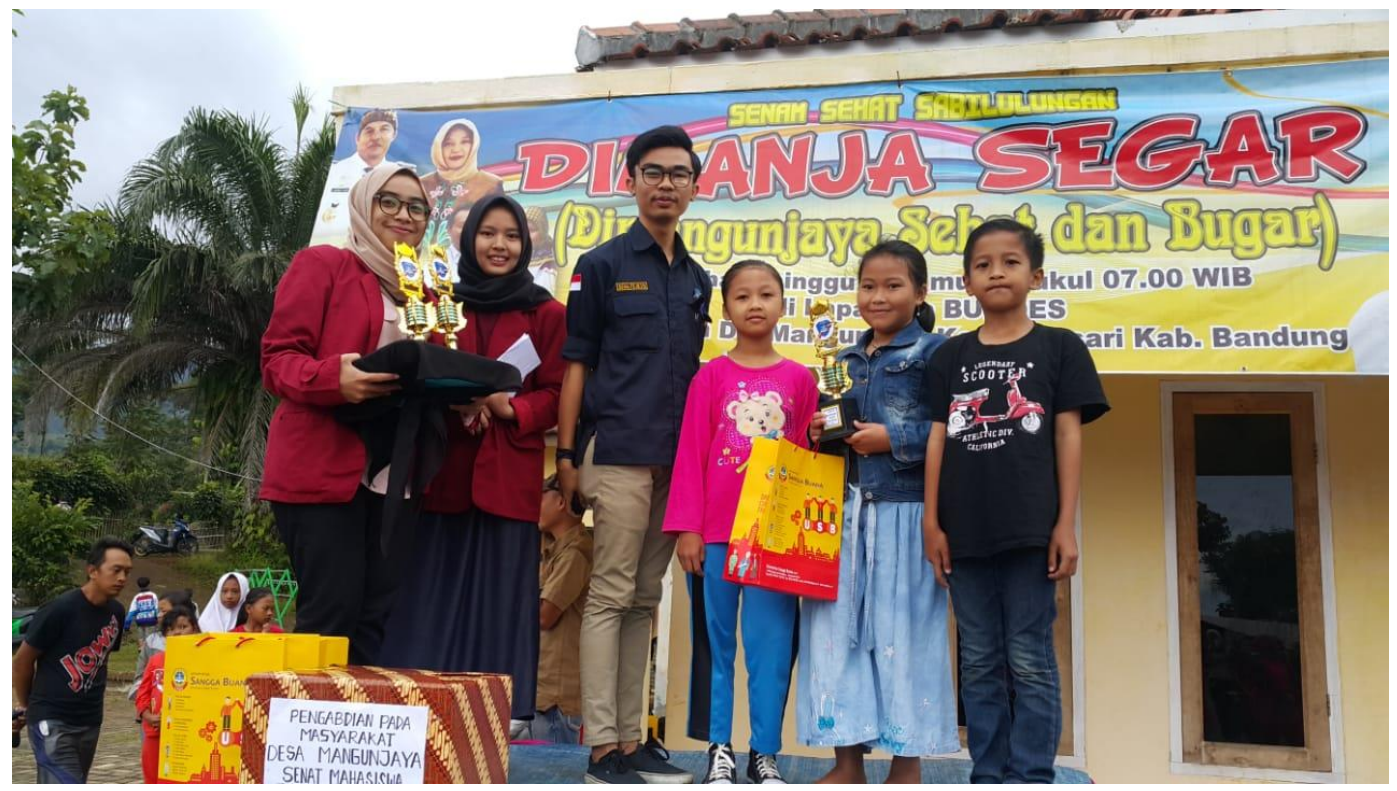

Gambar 5 : Para Pemenang Lomba Cerdas Cermat

Selama berada di Desa Mangunjaya, para anggota SEMA tidak pernah ketinggalan untuk melaksanakan shalat secara berjamaah di mesjid desa. Selain itu, dalam setiap harinya selalu ada agenda untuk membersihkan masjid ataupun daerah lingkungan desa lainnya secara gotongroyong dengan beberapa warga. Lalu, pada hari terakhir kegiatan, sebelum para anggota SEMA kembali pulang ke kampus, diadakan kegiatan Bazar baju dan sembako murah untuk warga desa Mangunjaya. 


\section{KESIMPULAN DAN SARAN}

Selama 4 hari berada di Desa Mangunjaya, para anggota SEMA Fakultas Ekonomi Universitas Sangga Buana telah melakukan berbagai macam kegiatan positif yang sangat bermanfaat, baik bagi warga Desa Mangunjaya, maupun bagi angggota SEMA itu sendiri. Dengan adanya kegiatan PKM ini, diharapkan dapat semakin menumbuhkan jiwa dan nilai sosial, serta penguatan karakter para anggota SEMA. Meskipun kegiatan PKM ini hanya merupakan suatu langkah kecil, tapi karena dilakukan dengan kepedulian yang besar dari anggota SEMA, semoga dapat dirasakan manfaatnya oleh warga Desa Mangunjaya. Kami juga berharap agar silaturahmi antara anggota SEMA Fakultas Ekonomi dan warga Desa Mangunjaya tetap terjaga, serta kegiatan
PKM seperti ini dapat dilakukan kembali di kemudian hari.

\section{DAFTAR PUSTAKA}

[1] Undang-Undang Nomor 12 Tahun 2012 tentang Pendidikan Tinggi

[2] Suwahyu, Irwansyah. "Pendidikan Karakter Dalam Konsep Pemikiran Pendidikan Ki Hajar Dewantara" INSANIA : Jurnal Pemikiran Alternatif Kependidikan, Vol. 23 No. 2, 2018.

[3] Mujib, Abdul, Nuansa-Nuansa Psikologi Islam, Jakarta: Raja Grafindo Persada, 2002.

[4] Usman, Husaini. Manejemen: Teori, Praktik, dan Riset Pendidikan. Jakarta: PT Bumi Aksara, 2006.

[5] Wulandari, Antonina Pantja Juni \& Astrini. "Peran Pendidikan Agama dan Kewarganegaraan di SMA dalam Meningkatkan Karakter Tangguh, Kompetitif dan Dinamis", Jurnal Psikologi Ulayat, Vol. 1 No. 2, 2013. 